\title{
FACILITATING COLLABORATION IN ONLINE LEARNING
}

\author{
Caroline Haythornthwaite \\ University of Illinois at Urbana-Champaign
}

\begin{abstract}
Collaboration entails working together toward a common goal, but what is the common goal we want students to work toward in classes? What kinds of interactions and outcomes do we value as collaboration, and how do we facilitate them? This paper addresses these questions, beginning with an examination of research on groups, community, and shared cognition that inform collaboration, and then addressing what we mean when by collaboration. Three questions define the discussion: Why do we emphasize collaboration and try to engage students in collaborative activities and collaborative learning? What outcomes do we expect from collaboration in terms of how students interact, tasks are conducted, learning accomplished, and knowledge created? How does communication differ online from offline, and how does the difference affect collaboration? Each section ends with some recommendations on how to facilitate collaboration, and the paper concludes with a brief summary and some key concepts for facilitating collaborative activity.
\end{abstract}

\section{KEYWORDS}

Collaboration, Engagement, Knowledge Creation, Facilitation

\section{INTRODUCTION}

Simply put, collaboration entails working together toward a common goal. But when we say we want students to collaborate, what does that actually mean? What is it we want them to collaborate on? What kinds of interactions and outcomes do we count as collaboration? How do we facilitate that collaboration in online learning networks?

These questions are addressed in this essay. The paper starts with a discussion of why we collaborate, and a brief look at the areas of research that provide information about collaborative processes, including research on groups, community, and shared cognition. These literatures draw our attention to the full range of interactions students are engaged in, and how many of these provide the underpinning for successful collaborative learning. Collaboration as discussed in this paper addresses learning and knowledge creation, group learning, development and maintenance processes, computer-mediated communication, and the presentation of these issues in online learning environments $[1,2,3,4,5,6,7]$.

The second section discusses what we mean when we say we want students to collaborate. This is an important definitional step because what is considered a successful collaboration affects not only what tasks are established but also how collaborative activity is evaluated, what technologies are used, and what social, cognitive, and teaching interventions are implemented to facilitate the collaboration. 
Three questions define the sections below:

- Why do we emphasize collaboration and try to engage students in collaborative activities and collaborative learning?

- What outcomes do we expect from collaboration in terms of how students interact, tasks are conducted, learning accomplished, and knowledge created?

- How does communication differ online from offline, and how does this affect collaboration?

Each section ends with some recommendations on how to facilitate collaboration, and the paper concludes with a brief summary and some key concepts for facilitating collaborative activity.

\section{WHY COLLABORATION?}

Why do we emphasize collaboration and try to engage students in collaborative activities and collaborative learning? Is it because, as social creatures, we gain increased quality of life by engaging in collaborative efforts, or is it because we gain learning, knowledge or work benefits from collaborative action $[8,9]$. If we gain benefits, what are they? If not, is it reason enough that collaboration will satisfy our craving for crave social interaction?

To answer these questions we can draw on research in a number of fields, although finally the choice about why we favor collaboration will be our own. There are indeed many good reasons for collaboration, and with an awareness of the many dimensions of collaboration, we are armed with a repertoire of possible goals for the collaboration, and with these goals we can then focus our efforts for facilitating the collaboration. Although a comprehensive review of the literature on collaboration is beyond the scope of this paper, the following highlights areas where discussion of collaboration is taking place, leading to a list of collaborative elements to be considered for supporting collaborative activities.

\section{A. Learning From Other Fields}

A number of areas of research discuss parts of the collaboration problem, including research and theory about collaborative learning, computer-supported collaborative learning (CSCL), knowledge construction, group learning, scientific and interdisciplinary collaboration, computer-mediated communication, online community, and computer-supported cooperative work. Research in each of these areas gives a piece of the puzzle toward facilitating collaboration, but each has its own emphasis. In addressing collaboration in online or asynchronous learning, it is important to consider what aspects of collaboration are most relevant for the application at hand, whether this is group trust, social bonding, creation of new knowledge, or learning, but without forgetting about background issues that support this kind of collaboration.

Management research suggests collaboration allows people to do more together than they could alone, thereby increasing the extent and efficiency of work organizations [8]. Much work in management and social psychology explores how groups work together, examining processes that lead to successful collaborations. Researchers explore temporal stages of group formation and maintenance [10, 11, 12, 13], how groups learn [14], how members gain knowledge about others in the group (transactive memory [15, $16])$, and the relation to technology use $[17,18]$.

This body of work emphasizes the need to plan and manage group development, expecting different kinds of interaction, information and support needs during the 'forming, storming, and norming' stages of 
development [20, 21], and the processes that McGrath [12] identifies in group work in which member: Generate (ideas, alternatives, plans), Choose (a correct or preferred option from alternatives), Negotiate (in the face of conflicting views and interests), and Execute (the work in the face of competition or with respect to some standard). Haythornthwaite, Kazmer, Robins, and Shoemaker [5] found similar development stages for online learners. Students showed stages of coming together, maintaining presence online, and disengaging from the online world, each of which required different kinds of support (see [22] for start-up issues for these students (also discussed below); see [23] for disengagement).

Other research explores knowledge issues, including how knowledge is acquired and created, and what kinds of knowledge individuals and groups acquire. Researchers in management (e.g., [23, 24, 25]) and in scientific and interdisciplinary collaboration (e.g., [26]) are interested how tacit knowledge is acquired, including practical 'know-how' as well as knowledge of how to practice, e.g., as a member of a particular discipline, or of a distributed organization. This work shows the many kinds of knowledge that are being acquired during learning and group work, including explicit and tacit knowledge, but also knowledge about how to work together as a group, and how to work together through technologies. For any online group, the last component is highly important-indeed, it should go at the top of the list rather than the end. Every online group must first determine how members will communicate and establish their own rules for communication before they can begin the collaborative or knowledge acquisition phases.

To progress in their work, groups need to create common understandings about their goals, the meaning of activities and concepts, and communication practices. Researchers sometimes refer to creating a 'third space' where disciplinary or job-specific approaches are suspended so new ideas and knowledge can flow from group interaction. Creating common practices and common meanings is the cornerstone of collaborative practices. Research that is relevant in this area includes the work on socially shared cognition [20, 27, 28], and interdisciplinarity [26, 29, 30].

Some of the barriers to creating common ground are the traditions and expectations about how work should be done in to collaborative efforts. Collaborators must first become aware of aspects of their work practice, and then explore differences to come to a joint understanding of group goals in light of participants' disciplinary or professional practices [31]. In online learning settings, students bring assumptions about how class work will progress that are based on face-to-face models of teaching and learning. Giving up those ideas may be very difficult, since students' sense of their progress and success may be tied to seeing the kinds of interactions they know from face-to-face classes. Thus, a class that never meets synchronously, or a grade based on group work, may represent a significant cognitive shift in what an individual perceives as a learning and educational outcome.

Other work that is relevant to knowledge processes includes studies of workplace practice (e.g., [32]), and activity theory [33]. Each of these addresses the kinds of knowledge that are embedded in group work and group practice. These studies show the detail of what gets done, processes that are very often invisible to those carrying them out [34]. They also show how what we do is bound up in the physical, technical, and social arrangements in which the work is embedded. Again, these are often invisible or taken-for-granted factors that impact how we go about our work. For instructors, the move from offline to online often reveals teaching practices, and instructors find themselves re-examining both their online and offline teaching practices [35]. However, students coming new to online environments have not had this time for reflection, and therefore need to be oriented to the new environment and its new practices.

A further area of consideration includes the social psychology and sociology of communities. Recent interest in communities of practice [36, 37, 38] stemming from ideas of apprenticeship learning and 
legitimate peripheral participation [39] resonate with issues relating to online learning and collaboration. Ruhleder \& Twidale [7] draw comparisons between learning in a community of practice, and in a Master Class (e.g., group music instruction with an accomplished performer):

"The format and pedagogical goals of a master class embody a set of principles compatible with Dewey's conceptualization of reflective learning. These classes take place within a community of practice that supports on-going collaborative learning that bridges the boundaries of the classroom” [7].

The authors use the master class analogy to look at online teaching and learning about interface design. They find that group participation and open presentation of individual learning brings the process to the surface, showing how products develop through interactions of design, helped along by collaboration in development.

An important point to note about new online endeavors is that those joining an online community of practice must actually join two communities-the knowledge (or discourse) community and the online practice community. Observing practice online is somewhat different from offline: FAQ lists (frequently asked questions) can be read, and individuals may spend time as lurkers to get to know how the community works, but neither makes the individual visible as they would be offline. Getting to know others is also different. Often the only visible traces of other people online are their text messages, whereas offline, cues such as body language, general deportment, and clique formations are visible and provide feedback to appropriate behavior as well as on an individual's place in the group. Consideration of community formation highlights the more subtle learning that occurs in groups relating to the presentation of the individual to that group, and the group's recognition of an individual as a member. One of the major challenges of any online environment is to build in such aspects of social presence and social navigation. This can be done by social and/or technical interventions such as creating a common area for discussion and actively seeding the discussion, or choosing to implement more immediate feedback such as can be provided in online office hours conducted in a chat room. Designing an environment that promotes social presence has been shown to lead to greater group cohesiveness and higher level critical thinking [40, 41, 42, 43].

\section{B. Collaborative Learning}

Why collaborative learning? The underlying assumption for educators is that collaborative learning holds the promise of active construction of knowledge, enhanced problem articulation, and benefits in exploring and sharing information and knowledge gained from peer-to-peer communication [9, 44, 45, 46]. New knowledge can be built from the pooling of ideas and information, and actively testing these against the ideas of others [23]. As Garrison states, "the goal of the collaboration is to create a community of inquiry where students are fully engaged in collaboratively constructing meaningful and worthwhile knowledge” [47].

Collaboration also models the way work unfolds outside classrooms. It can emulate and train for future workplace practices, including learning how to share ideas, voice opinions, work on a team, and manage projects. It gives individuals experience in project and group management. Moreover, during their collaboration, students are also doing the important work of learning how to do all this online and gaining skills in online communication and group management.

Although not often discussed in relation to learning, collaboration also addresses needs for social interaction. Talking and communicating with others can help individuals feel part of a community, and thus provide a set of others to reach out to for social support in times of need [5]. Such interaction 
increases feelings of belonging to a class, commitment to group goals, and trust among group members [12]. This aspect is particularly important for distributed students who cannot meet in the conventional on-campus classroom, hallways and coffee shops.

Thus, collaborative group interaction in educational settings promotes these positive outcomes: active learning (following constructivist learning theory, [48]); co-construction of knowledge [49]; emulation of expected future workplace requirements; social interaction and a learning community [6,50,51]; and a sense of belonging [5].

\section{Limits to Collaboration}

The benefits of collaboration look good, but what are the limits to collaborative activity? With all the positive potential outcomes from successful information and knowledge sharing expected from an optimal collaboration, it is easy to forget that such peer-to-peer exchange depends on time, effort, and trust among peers. Sharing may not occur when there is competition for scarce resources, where knowledge is power, or where time is so short that engagement with peers is outside the bounds of possibility.

Few consider that there might be too much sharing, and thus too much of a load on individuals placed in a collaborative context. For example in the Graduate School of Library Science (GSLIS) LEEP program at the University of Illinois at Urbana Champaign, the required class for the degree program, which is typically taught online in two sections of approximately 35 students, generates around 3500 messages per section (average size of about $1 \mathrm{k}$ ) that a student will see, and approximately 7000 messages for the instructor and teaching assistants to review. These numbers do not include chat messages or emails among class members or to and from instructors, the count for other classes the students may be taking concurrently, or the assignment submissions. Nor do these numbers indicate attributes of overload associated with the number of threads to follow, the number of other people to keep track of, sorting through messages for relevant content, and the amount of non-course communication students engage in. Finally, these numbers do not show the load of activities happening to students who are "in class" while simultaneously immersed in non-classroom settings, e.g., at home or at work (see $[52,53])$.

Sharing may also be too wide ranging, and too encompassing. The reduced cues of the CMC environment lead some students to reveal more personal information than they would face-to-face (Betsy Hearne, personal communication). More intimate details may be shared online, putting a social and emotional burden on posters and others. "School" may not always be emotionally neutral. Others may use the forum as a way to gain social contact, and what they are sharing may not be related to the supposed purpose of the class, adding to the number of messages and amount of information posted.

Added to this is the short-term nature of most collaborations in online learning settings. Individuals are thrown together in groups for short term outcomes such as directing a discussion, or completing an endof-semester project. While collaborative learning does not require long term interaction to be useful and effective, building trust and an online community that promotes collaboration does. Overall, we may find that for short term attendees, task completion is at odds with the creation of the kind of environment that engenders collaboration [54]. Getting to know others takes time, and this is often not factored into schedules for group projects. Also, working online can take more time, so the combined effect may be more pronounced for online than offline groups. 


\section{Recommendations}

Overall, there are many possible benefits from collaborative activity related to learning, modeling the workplace, and creation of new knowledge, but these may be weighed down by the overload and overexposure associated with online learning. Thus, the first caveat is how to facilitate the right amount of collaboration and sharing online, considering who should be involved in the learning collaboration, for what reasons, and for how long. The following are some recommendations on what to be aware of when considering how to manage the amount of collaborative activity:

- Be aware of the model students have of how class work progresses and work with that to 'sell' the change from individual, proprietary, single-owner work to joint, collaborative work.

- Factor in the extra time needed to collaborate and to collaborate online when establishing course requirements.

- Make students aware of the collaborative process, including the need to get to know others, create common goals, and establish their own communication practices.

- Make students aware of the differences between offline and online work and learning practices.

- Keep message load manageable by limiting class or group sizes, and by creating 'small within the large’ both for groups within larger classes, and for message threads within larger topics.

- Teach collaborative online skills as part of the practice of being an online student: e.g., use of conventions such as message subject headings, proper message thread use in bulletin boards, topic management.

\section{WHAT DO WE MEAN BY COLLABORATION?}

So far we have discussed collaboration in general, as if there were one model we were aiming to implement and achieve. However, while the overall goal may be to use collaboration to create a community of inquiry with fully engaged students, there are many ways to get there. Collaborative practices come in various forms, from division of labor to joint construction, from application of knowledge to creation of shared, co-constructed knowledge. When we set out to facilitate collaborative learning, what outcomes do we expect in terms of how students interact, tasks are conducted, learning accomplished, and knowledge created? This section describes some of the dimensions that affect collaborative activity and which suggest different needs for social and technical support. By understanding what we mean by collaboration, we can also then evaluate whether the techniques have achieved that kind of collaboration, as well as considering the modeling and reward systems that need to be in place to promote that kind of collaborative activity.

Perhaps the biggest difference in terms of assessing collaborative efforts is whether we are content if students coordinate their activities, doing piecework that is later assembled into a whole, or passing pieces from one person to another in an assembly line model. In the latter case, the task is to support coordinated activity, including division of labor, packaging of tasks, scheduling, and allocating roles. In the result, each contributor's part is identifiable and separable, easily assessed as the work of the individual. However, we may not be content unless students achieve collaboration, involving joint work on tasks, creation of shared definitions, pooling and sharing of knowledge, and creation of emergent outcomes. In this case, the task is to support communication, the sharing of data, joint writing, and the creation of common knowledge. In this model, no single hand is visible in the final product, and thus assessment is of the work of the group as a whole, not of any individual.

This distinction between coordinated and collaborative action is not meant to privilege one kind over the other. There are legitimate reasons and occasions for each type of practice, and groups may use one or the 
other at different stages of their association. However, these two ends of collaborative action represent an important fundamental difference in process and goals, and thus in the kinds of social and technical support that are needed, and the evaluation of products such as assignments, quality of thought, project time to completion, etc. Each aligns with different purposes for promoting collaboration, e.g., modeling the commercial workplace where coordination may be more highly prized and rewarded than collaboration, or modeling some ideal of a research and development, or academic workplace, where collaboration is the highly-prized, but elusive, goal.

A second dimension of importance is what model of knowledge use we have in mind. Are we looking for a learning outcome in which knowledge is applied or constructed? Are learners expected to apply what they know in order to accomplish a task, or does the task itself require coming to a shared and joint understanding, thereby creating knowledge? The distinction between applied versus constructed knowledge is similar to a distinction made in the management literature between conditions characterized by uncertainty versus those characterized by equivocality $[55,56]$. In the former, the rules of how to proceed are known and what is needed is to get the information necessary to apply the rule. By contrast, under equivocality, the rules must be determined, and tasks are characterized by negotiation, including the negotiation of what the problem is before addressing it.

The difference between these learning outcomes may be illustrated in what experts can do together versus what novices can do [57], and the challenges experts face in crossing disciplinary domains [58]. Experts in the same field speak the same language, know how to break down tasks, and know how others in their field are likely to break down tasks, while novices must learn how and what to learn at the same time as engaging in collaboration. Experts crossing domains must become aware of and learn others' language, procedures, and approaches - a process that takes time. Tensions between learning and getting the task done can adversely affect collaboration, as can failing to recognize the complexity and the extra time needed to learn, create common ground, and complete tasks [31, 58]. Similarly, stated or unstated differences around the meaning of terms, culture, and language can slow and/or inhibit collaborative activity $[59,60]$.

In an applied knowledge scenario, we assume that each individual already has enough knowledge to be able to begin the task. Individuals are learning how to apply this knowledge in practice. Thus, advanced students may apply theory to a novel situation, critical thinking to a reading, writing skills to a project, or methodology skills to a research project. In trying out their acquired knowledge against the 'facilities and frustrations of the world' they are learning 'know-how' (tacit knowledge) and advancing the use of these skills in practice [23, 25]. Students' collaboration may be in helping bring everyone to the same level of explicit knowledge, sharing experiences, and comparing cases. Success depends on good communication and information delivery between collaborators as they apply the knowledge they have to the problem at hand.

In a constructed knowledge scenario, knowledge is acquired and/or created during the process of collaboration. A process of negotiation will be needed among collaborators to delimit the task, agree on goals, and come to shared meanings. Good communication is even more important because collaborators need to create of a common language, a "third space" perhaps, where shared understanding can be created. Building a common language adds complexity to the collaboration process since negotiating meaning requires more discussion and a greater need for clarity than passing on information; negotiations like these determine the kinds of technologies that are needed to support this kind of process, particularly in the ability to give and get feedback. 
The uncertainty/equivocality dimension and the need for immediate feedback formed the basis of Daft \& Lengel's [55] media richness theory. Although Daft \& Lengel did not themselves address computer media, the idea that rich communications - those requiring multiple communication cues, and immediate feedback - should be conveyed through rich media, became a major influence in the early days of computer-mediated communication. Text-based email was considered too lean for emotional, supportive, intimate or complex information exchange. Although times have changed and email and other text-based communications are considered appropriate for whatever communications we feel like exchanging, there is still a large difference between online and offline communication. As the use of computer media becomes second nature to most of us, we are in danger of forgetting the learned behaviors associated with them, and thus the ways of facilitating interaction are in danger of becoming invisible to us, just as they were for face-to-face classes. We return to this discussion below.

Awareness of the kind of collaboration needs to be taken into consideration for the design of the learning scenario. Of factors to consider, the type and timing of learning tasks can be expected to affect collaborative outcomes. Learning scenarios range from completely flexible, student-controlled learning to highly structured, instructor-controlled learning. In the former, students may need to grapple with all the details of dividing the work into stages, facilitating communication among team members, and project management. In the latter, many of these details may be taken on by the instructor, leaving the students to deal only with the cognitive issues. Aviv, Erlich, Ravid \& Geva [40] find some evidence that the instructor-led scenario provides higher levels of cognitive presence in the case of well-defined, collaborative projects. Perhaps highly structured projects enable students to concentrate on the cognitive aspect since the project and group management aspects have been minimized. Aviv et al. suggest, however, that this approach can be criticized for inhibiting creativity. Work on collaborative research teams suggests a similar trade-off: when teams must learn about each other, and each other's work, all stages take longer, adding to the time it takes to get work done [61].

Other work has shown that instructor choice of joint work can affect patterns of who talks to whom in classes. Classes that establish semester-long projects can reduce the collaborative network from that of the whole class to only members of the project group [54,62]. In large classes this may be a positive strategy for forming collaborative activity, but for smaller classes this may unnecessarily reduce the interaction and information exchange that might occur.

The way the learning scenario interacts with social networks and group communication indicates a third issue for collaboration, strong-tie collaboration and/or weak-tie collaboration. In establishing collaborative scenarios, if we only think of collaboration in terms of strongly tied, frequently interacting, group and community members, we miss the collaborative benefits of interaction among weakly tied participants. Research on information dissemination through social networks has found that new information tends to come to us from people we know as acquaintances rather than from our stronger, friend or family ties. This is because relative strangers know people in different social circles from our close ties, and thus have access to different information than we and our close friends do. The 'strength of weak ties' [63] suggests that where collaborative learning is about hearing new opinions and being exposed to new information (e.g., [44]) it is about weak-tie rather than strong-tie connections. Haythornthwaite [62] discusses the way views of collaborative learning that stress exposure to new information are at odds with the kinds of relationships and tasks instituted as collaborative group work. Both kinds of collaboration have their place and their merits, but the weak tie benefits should not be lost in a rush to implement strong-tie, small group collaborative tasks and activities.

We should not leave this discussion of collaboration without also tying its success to the reward systems that are in place for the work. Collaboration in whatever form we choose to pursue will only occur to the 
extent that it benefits individuals, either by helping them get work done faster and easier, increasing their learning outcomes, increasing satisfaction in the online and learning experience, or garnering rewards such as grades or recognition. A direct tie between collaborative outcomes and course content and collaborative activity helps attain collaborative goals. Student performance can be assessed by determining the tasks to reward, and then examining and rewarding online discussion that displays this (e.g., rewarding help giving), as well as implementing assessment of these tasks into grading rubrics [64]. Experiments have also been conducted on devising collaboratively determined exams [65]. Assessment aspects of collaboration are discussed in detail in the chapter by Swan, Shen \& Hiltz [64] in this issue. Instructors and researchers can assess the extent of desired collaborative outcomes by examining assignments and online discussions [1, 11], and assessing perceived learning [66, 67]. Level of cooperation and interaction can be assessed by participation analysis [68], and structural network analysis $[41,62,69,70,71]$.

\section{A. Recommendations}

Thus, to facilitate collaboration, it is first necessary to be aware of the possible kinds of collaborative activity, and decide which model to promote. This leads to these recommendations:

- Be aware of different models of collaborative activity, ranging from coordination individual activity to group based knowledge creation.

- Consider when, and for what kinds of tasks, each kind of collaborative activity is appropriate.

- Consider what kind(s) of collaboration to promote in relation to the desired knowledge and learning outcome(s).

- Accommodate and reward each kind of collaboration appropriately.

- Consider who will get the credit for (a) the work done, (b) the collaborative activity, and accommodate and reward appropriately.

- Monitor collaborative activity as a dimension of teaching, e.g., monitor collaboration as it unfolds by asking groups how they are managing their work and what they are achieving, or examining records of group work where recorded in bulletin boards or chat rooms.

- Engage students in monitoring their own collaborative activity, e.g., with progress reports, descriptions of group activity.

- Maintain the benefits of weak-tie collaborative activity when designing collaborative tasks.

\section{COMPUTER-MEDIATED COMMUNICATION AND COLLABORATION}

How does communication differ online from offline, and how does this affect collaboration? Much has been written in dystopic and utopic terms about the transformative nature of computer-mediated communication (CMC). CMC is labeled as an insufficiently rich mode of communication to sustain community and engender trust relations, and one in which the reduced cues and relative anonymity has a disruptive, disinhibiting impact on communication behaviors (e.g., flaming) and presentation of identity online. On the other hand, the lack of cues, anonymity and asynchronous communication capabilities are cited as delivering positive effects as communicators can express themselves more freely, take on and perform new and different roles online, and allow participants separated in time and space to occupy the same cyberspace. (For reviews of the way communication via computer-media differs from face-to-face communication and how this affects group and collaborative behaviors, see [72, 73, 74, 75, 76].) 
Although many still feel CMC to be an impoverished environment compared to face-to-face communication, its widespread use requires us to put our efforts toward how to use CMC rather than continuing to debate its relative merits in comparison to offline communication. Former debates also treated discussion of CMC and the Internet as if they were totally separate realms. However, our reality is more and more that we mix CMC with other communications, and these become complementary means of achieving social outcomes. As interest grows in blended learning, it is important to address how online and offline communications complement each other, an area in need of more research particularly with respect to learning settings (for discussion of online/offline synergies, see [77].)

Communication via computer-media, whether better or worse than face-to-face, comes with its own affordances which can enhance or impede collaborative activity in learning settings. Studies of online learners found that three "radicals of presentation"-visibility, speaker-audience relation, and co-presence with others-played out as key factors affecting students' comfort and willingness to share information and contribute online [22, 78]. Visibility became an issue because students feared exposure of their prose before they had learned how to "talk" online. Their found that their class conversations had become "persistent conversations" ([79]; see also work of Susan Herring, e.g., [73]), making their process of learning to use the technology to communicate both visible and permanent. Students were also concerned about being co-present with other students or the instructor. Many feel the need to make a connection with others, to experience the immediacy of a chat room or live class, and to engage in interactive communication (for more on interactivity and CMC, see the work by Sheizaf Rafaeli, e.g., [80]). Synchronous and near-synchronous communications have great importance in sustaining individuals' attention, attachment to group and community, and satisfaction with the online experience [5].

The factors that make it possible for students to communicate and collaborate online are not just technical. Underlying principles of interactivity, presence, and socialization are at work, playing equal roles in offline collaboration. But the difficulties reflect the way technology choices combine with expectations to create barriers that have to be overcome by individual students. For example, students face the dilemma that comments during class are normally ephemeral, yet chat rooms keep a record of these conversations. At the same time, students know there are conventions for submitting class work, yet do not know what the convention is for bulletin board posting or chat room comment. Each time they 'talk' in class they are debating whether this is like assignment work, or like participation. Should they type as if they were talking or as if they were writing?

There are no set of communication "rules" to hand to newcomers to deal with these dilemmas. Students across online programs, individual courses, and collaborating sub-groups, develop their own communication styles and practices, co-constructing ways of writing, posting, and conversing online for their particular time and place (in a process of social construction, or "adaptive structuration,"'[81]. The responsibility lies with the communicators to establish communication conventions.

Students also consider who the audience is for their posts: the whole class, a subset of class members or an individual; a class of friends or a group of strangers; students or instructors. Research on use of multiple media in online classes shows that communication practices differ according to the nature of the interpersonal ties between communicators. Close friends use more kinds of media to communicate, extending their range of contact times and means [62]. Students may use the extended, usually private or limited distribution, means of communication to ask for help they would not otherwise ask for before the whole class. Online friends become important sources of both class-related information and social support [5]. 
By contrast, strangers and acquaintances use only the means of communication established for the class as a whole, restricting their interaction to one or at most two media. The differential use of channels to communicate with class acquaintances versus good friends means that those who do not have a close interpersonal tie depend on the class-mandated media for all their interaction. These findings indicate the importance of teaching presence: responsibility lies with the organizers of the class to choose the right social and technical connection for effective class interaction and collaboration. Instructor choices about social and technical connections lay the groundwork for latent ties among new class members - ties that are technically available, yet not activated socially, and on which stronger relationships may grow. Thus, instructor choices are responsible for creating the patterns of interaction on which trust, community, and collaboration are built [54, 62, 82].

Aviv, Erlich \& Ravid [69] note a few cautions about in-class interaction, finding that students tend to reciprocate queries and responses, which results in questions and answers conducted to and from a single participant. Aviv and colleagues [69, 83] also found that efficiency consideration of students' hunt for knowledge decreases their tendencies to collaborate via broadcast forums, but strong team design provides peer pressure which can overcome that tendency.

\section{A. Recommendations}

The following recommendations are made for facilitating online collaborative activity:

- Promote an information sharing culture.

- Model group norms, setting some, but letting others emerge.

- Model good communication behaviors.

- Establish social and/or technical means for synchronous or near-synchronous communication.

- Provide means for faster feedback, e.g., establish ways for students to assemble synchronously or near synchronously (such as in chat rooms during set hours) for more immediate feedback sessions when most students can be present.

- Build community capacity by providing means for students to socialize and get to know each other, e.g., in bulletin boards for non-class discussion, where they are free to exchange information on how to manage in an online environment, and in this online experience.

- Provide both public and private means of communication: balance the public and the private so not all communications at all times are recorded for public review, and/or allow places and spaces for informal, non-recorded online conversation.

\section{B. Examples}

A few examples from accomplished teachers' and program practices may help to make concrete some of the recommendations made here.

Preliminary orientation to the group, cohort and program during a two-week on-campus session prior to the beginning of the first semester has proved to be one of the mainstays of GSLIS' LEEP program. Students, faculty, and program evaluators all find that the preliminary gathering, affectionately called "boot camp" by attendees, lays the foundation in trust, and interpersonal connections that sustains students at a distance [84], marked by humor, group memories, and experiences that create a shared world with its own history and folklore [85]. Although not all programs can take up the on-campus model, the LEEP experiences speaks well to the value of providing an in-depth orientation to the new learning 
environment, its rules and conventions, and most importantly, the fellow students with whom individuals will collaborate with, learn from, and commiserate with in the future (see also [38]).

Synchronicity is important even when accomplished at a distance. In exploring best practices in LEEP, Lawton \& Montague [84] note that five aspects dominate: (1) orientation, also known as boot camp, (2) on-campus sessions (face-to-face), (3) group work, (4) synchronous sessions (live sessions), (5) order and organization. Three of these involve synchronous activity; a time when questions to an instructor can be answered immediately, but also when students can ask each other what is going on. Communication flows change during synchronous sessions, and indeed change the flow significantly from the face-to-face one question-one answer sequencing (see also [86]). As Lawton \& Montague note:

"Perhaps the most blatant yet subtle example of this is the whisper function available in chat sessions. By clicking on a name or names of others in the class, chat room participants can send private messages to others in the chat room. Similar to passing notes across the aisle in a face-to-face classroom, this behavior may seem problematic or even disrespectful. However, students reassured concerned faculty at the retreat by explaining they use this function principally to clarify issues, and that this action reflected a conscientious sense of self- and peer monitoring” [84].

Synchronicity is accomplished in LEEP through set lecture hours where students can gather and listen to a live audio broadcast, asking questions to instructors and each other via the class chat room. Live office hours also provide time for connections, as do the on-campus mid-term meetings.

Again, not all programs can make use of synchronous sessions. Issues of scheduling, particularly across wide time-zone differences are an issue. One should look instead to the synchronicity for what it says about what students need in order to collaborate, i.e., contact with each other, feedback on questions and procedures.

Three instructors at different programs suggest ways to achieve this. Michelle Kazmer, teaching at Florida State University with no synchronous component to the class, establishes establish a "Q\&A" discussion board for each assignment. Students are instructed to post any questions about the assignments thererather than asking the instructor individually via email. This accomplishes the visibility of process noted as important by Ruhleder \& Twidale [7]. Some further aspects of the task ensure collaboration:

In addition, students are to answer one another's questions. All students are required to read the QA boards, and assignments are marked with the stated assumption that every student has read all QA posts. I read the QA boards frequently and carefully to ensure that students are not getting off track in their answers to one another. I jump in with corrections quickly if that happens. As well, I answer any questions left open for more than a day or so (less if it is close to the due date).

I have used the QA board technique now for 6 semesters and it works extremely well in encouraging students to learn collaboratively. It leverages the well-known idea that one learns something better by explaining it to others, and thus benefits students who answer questions. It helps students who ask questions, of course. Also, students who think they are not confused often benefit by seeing other students' questions and answers, because they realize that they were really confused to begin with! (Kazmer, email communication) 
Michael Twidale, a GSLIS faculty member and LEEP instructor, reports that the main thing he depends on in promoting collaboration in his classes is the groundwork laid in the boot camp sessions. As he notes "Throwing gas on a fire is way less work than rubbing two sticks together" (email communication). Twidale works diligently on reading and adding to the collaboration that has been initiated as part of class structures and assignments. First, he says,

I make them aware that typed comments into my live talks [e.g., into the chat room during class audio broadcasts] do have an impact. So they know I'll get on to their comment even if out of order or at an appropriate juncture in my spiel.

In live sessions I do the usual: split them up in small groups, send them off to different chat rooms to discuss and then nominate reporters to feed back into the plenary. I comment on their posts, the rest chip in with elaborations, I generalize. With 3-5 in a room chatting they all pretty much have to say something. I can easily look and simultaneously read discussions in 5 simultaneous chat rooms since I can read faster than they can type and of course I'm prepped. I can even type the odd few words or question to help along a group that's stuck. (Twidale, email communication)

Active engagement and participation by the instructor, who now acts more like a facilitator than an instructor, leaves the space for students to create their own collaborations, without abdicating the instructor role.

Jenny Robins at Central Missouri State University brings in student's local experiences to encourage and motivate participation,

I just had a student in my reference class tell us that she has a new school library where there is no reference collection, but there is money to build a collection. I think of this as a golden opportunity to enlist the class to come to her aid. Having an authentic purpose and the opportunity to serve a fellow student are fairly irresistible. I expect to see collaboration arise from this. (Robins, email communication)

In their practices, all three include credit for collaboration in the final grade. As Lawton \& Montague [84] note, "Group work is the practice that everyone loves to hate", and so mandates coupled with reward help the collaboration take place. Kazmer ties grades to response of the group Q\&A board; Twidale ties grades to at least one assignment each semester and to participation in group work during classes; and Robins also ties grades to participation and responding to each other each week. Lawton \& Montague report that instructors can help students in achieving successful collaborations in their group work by providing clear and comprehensive instructions in advance. Guidance includes more than the intellectual content; just as importantly, student need help in the process of collaboration: "Students want guidance on how to function within the groups, what to do and what is expected of them, and when and how they will be evaluated. Students are strongly opposed to evaluating one another and adamantly in favor of regular and thoughtful feedback from faculty.”

These few examples bring into online teaching practice recommendations noted in this paper. They show that collaboration is possible and successful with a combination of attention to social and technical facilitation, appropriate rewards, active facilitation by instructors, with enough space left for students to create their own collaborative behaviors and communities of practice. 


\section{SUMMARY: MAJOR ISSUES FOR COLLABORATIVE LEARNING}

To reiterate, research and theory on learning, groups, collaboration, and computer-mediated communication provide background on the many kinds of issues that affect the form and purpose of collaborative activity. This paper set out to expand the scope of collaboration from consideration of learning about content to consideration of the wider context of trust in groups, development of an online, knowledge community, and promotion of collaborative work habits. Since collaboration can mean many things, instructors are encouraged to understand the collaboration they have in mind and to plan accordingly, with the facilities and frustrations of the online environment continuously in mind.

\section{REFERENCES}

1. Aviv, R. Educational performance of ALN via content analysis. Journal of Asynchronous Learning Networks 4(2): 53-72, 2000.

2. Garrison, D. R., and T. Anderson. E-learning in the 21st Century: A Framework for Research and Practice. RoutledgeFalmer, NY: 2003.

3. Gunawardena, C. N., C. A. Low, and T. A. Anderson. Analysis of global online debate and the development of an interaction analysis model for examining social construction of knowledge in computer conferencing. Journal of Educational Computing Research 17(4): 397-431, 1997.

4. Haythornthwaite, C. and M. M. Kazmer. (Eds.) Learning, Culture and Community in Online Education: Research and Practice. NY: Peter Lang: 2004.

5. Haythornthwaite, C., M. M. Kazmer, J. Robins, and S. Shoemaker. Community development among distance learners: Temporal and technological dimensions. Journal of Computer-Mediated Communication 6(1): 2000. Online: http://www.ascusc.org/jcmc/vol6/issue1/haythornthwaite.html.

6. Hiltz, S. R. Collaborative Learning in Asynchronous Learning Networks: Building Learning Communities. "Web98” Orlando: Florida, 1998. Online: http://web.njit.edu/ hiltz/collaborative learning in asynch.htm.

7. Ruhleder, K. and M. Twidale. Reflective collaborative learning on the web: Drawing on the master class, First Monday 5(5): 2000. Online: http://firstmonday.org/issues/issue5_5/ruhleder/index .html.

8. Argyle, M. Cooperation in working groups. Cooperation: The Basis of Sociability, 115-131. London: Rutledge, 1991.

9. Koschmann, T. (Ed.) CSCL: Theory and Practice of an Emerging Paradigm. Mahwah, NJ: Lawrence Erlbaum, 1996.

10. Chidambaram, L. and R. P. Bostrom. Group development (I): A review and synthesis of developmental models. Group Decision and Negotiation 6(2): 59-187, 1997.

11. Gunawardena, C. N. and F. Zittle. Social presence as a predictor of satisfaction within a computer mediated conferencing environment. American Journal of Distance Education 11: 8-26, 1997.

12. McGrath, J. E. Groups, Interaction and Performance. Englewood Cliffs, NJ: Prentice-Hall, 1984.

13. McGrath, J. E. Time matters in groups. In J. Galegher, R. E. Kraut and C. Egido (Eds.), Intellectual Teamwork: Social and Technological Foundations of Cooperative Work, 23-61. Hillsdale: Lawrence Erlbaum Associates, 1990.

14. Argote, L. D. Gruenfeld, and C. Naquin. Group learning in organizations. In M. E. Turner (Ed.), Groups at Work: Theory and Research, 369-411. Mahwah, NJ: Lawrence Erlbaum, 2001.

15. Wegner, D. Transactive memory: A contemporary analysis of the group mind. In B. Mullen \& G. Goethals (Eds.), Theories of Group Behavior, 185-208. New York: Springer-Verlag, 1987.

16. Moreland, R. Transactive memory: Learning who knows what in work groups and organizations. In L. Thompson, J. Levine, and D. Messick (Eds.), Shared Cognition in Organizations, 3-31. Lawrence Erlbaum Associates, 1999.

17. Chidambaram, L. and R. P. Bostrom. Group development (II): Implications for GSS research and practice. Group Decision and Negotiation 6(3): 231-254, 1997. 
18. McGrath, J. E., and A. B. Hollingshead. Groups Interacting with Technology. Beverly Hills, CA: Sage, 1994.

19. Hollingshead, A. B. and N. S. Contractor. New media and organizing at the group level. In L. Lievrouw and S. Livingstone (Eds). Handbook of New Media, 221-235. Thousand Oaks, CA: Sage, 2002.

20. Thompson, L., J. M. Levine, and D. M. Messick (Eds.). Shared Cognition in Organizations: The Management of Knowledge. Mahwah, NJ: Lawrence Erlbaum, 1999.

21. Tuckman, B. W. Developmental sequence in small groups. Psychological Bulletin 63: 384-399, 1965.

22. Bregman, A. and C. Haythornthwaite. Radicals of presentation: Visibility, relation, and copresence in persistent conversation. New Media and Society 5(1): 117-140, 2003.

23. Cook, S. D. N, and J. S. Brown. Bridging epistemologies: The generative dance between organizational knowledge and organizational knowing. Organization Science 10(4): 381-400, 1999.

24. Kazmer, M. M. Beyond C U L8R: Disengaging from online social worlds. New Media and Society. In press.

25. Nonaka, I. A dynamic theory of organizational knowledge creation. Organization Science 5(1): 14 37, 1994.

26. Orlikowski, W. J. Knowing in practice: Enacting a collective capability in distributed organizing. Organization Science 13(3): 249-273, 2002.

27. Klein, J. T. Interdisciplinarity: History, theory, and practice. Detroit: Wayne State University, 1990.

28. Brown, J. S., A. Collins, and P. Duguid. Situated cognition and the culture of learning. Educational Researcher 18(1): 32-42, 1989.

29. Resnick, L. B. J. M. Levine, and S. D. Teasdale (Eds.). Perspectives on Socially Shared Cognition. Washington, D.C.: American Psychological Association, 1991.

30. Klein, J. T. Crossing Boundaries: Knowledge, Disciplinarities, and Interdisciplinarities. University Press of Virginia, 1996.

31. National Academy of Sciences, National Academy of Engineering, and Institute of Medicine. Facilitating Interdisciplinary Research. Washington, DC: National Academies Press, 2005.

32. Haythornthwaite, C. Communicating Knowledge: Articulating Divides in Distributed Knowledge Practice. International Communication Assoc., New Orleans, LA, 2004.

33. Suchman, L. Plans and Situated Actions: The Problem of Human-Machine Communication. Cambridge: Cambridge University Press, 1987.

34. Star, S. L. and A. Strauss. Layers of silence, arenas of voice: The ecology of visible and invisible work. CSCW 8 (1/2): 9-30, 1999.

35. Montague, R. and. L. C. Smith. Faculty perspectives. In C. Haythornthwaite and M. M. Kazmer (Eds.), Learning, Culture and Community in Online Education: Research and Practice, 215-227. NY: Peter Lang, 2004.

36. Wenger, E. Communities of Practice: Learning, Meaning, and Identity. Cambridge, UK: Cambridge University Press, 1998.

37. Wenger, E., R. McDermott, and W. M. Snyder. Cultivating Communities of Practice. Cambridge, MA: Harvard Business School Press, 2002.

38. Davenport, E. and H. Hall. Organizational knowledge and communities of practice. Annual Review of Information Science and Technology 36: 171-227, 2002.

39. Lave, J. and E. Wenger. Situated Learning: Legitimate Peripheral Participation. Cambridge, UK: Cambridge University Press, 1991.

40. Aviv, R., Z, Erlich, G. Ravid, and A. Geva. Network analysis of knowledge construction in asynchronous learning networks. Journal of Asynchronous Learning Networks 7(3): 1-23, 2003.

41. Aviv, R., Z. Erlich, and G. Ravid. Response neighborhoods in online learning networks: A quantitative analysis, Educational Technology \& Society 8(4): 2005. 
42. Polhemous, L., L. F. Shih, and K. Swan. Virtual Interactivity: The Representation of Social Presence in an Online Discussion. Paper presented at the Annual Meeting of the American Educational Research Association, 2001.

43. Swan, K. Virtual interactivity: Design factors affecting student satisfaction and perceived learning in asynchronous online courses. Distance Education 22: 306-331, 2001.

44. Bruffee, K. A. Collaborative Learning: Higher Education, Interdependence, and the Authority of Knowledge. Baltimore: John Hopkins University Press, 1993.

45. Dede, C. J. The evolution of distance learning: Technology-mediated interactive learning. Journal of Research on Computing in Education 22(3): 247-264, 1990.

46. Harasim, L., S. R. Hiltz, L. Teles and M. Turoff. Learning Networks: A Field Guide to Teaching and Learning Online. Cambridge, MA: The MIT Press, 1995.

47. Garrison, D. R. Learning Collaboration Principles. Paper presented for the Sloan-C Summer Workshop, Victoria, BC, Canada, 2005.

48. Jonassen, D. H. Thinking technology: Toward a constructivist design model. Educational Technology 34(4): 34-37, 2004.

49. Scardamalia, M. and C. Bereiter. Computer support for knowledge-building communities. In T. Koschmann (Ed.) CSCL: Theory and Practice of an Emerging Paradigm, 249-268. Mahwah, NJ: Lawrence Erlbaum, 1996.

50. Renninger, A., and W. Shumar (Eds.). Building Virtual Communities: Learning and Change in Cyberspace. Cambridge, UK: Cambridge University Press, 2002.

51. Riel, M. and L. Polin. Online learning communities: Common ground and critical differences in designing technical environments. In S. A. Barab, R. Kling, and J.H. Gray (Eds.). Designing for Virtual Communities in the Service of Learning, 16-50. Cambridge UK: Cambridge University Press, 2004.

52. Kazmer, M. M. and. C. Haythornthwaite. Juggling multiple social worlds: Distance students on and offline. American Behavioral Scientist 45(3): 510-529, 2001.

53. Salaff, J. Where home is the office: The new form of flexible work. In B. Wellman \& C. Haythornthwaite (Eds.), The Internet in Everyday Life, 464-495. Oxford, UK: Blackwell, 2002.

54. Haythornthwaite, C. Building social networks via computer networks: Creating and sustaining distributed learning communities. In K.A. Renninger and W. Shumar, Building Virtual Communities: Learning and Change in Cyberspace, 159-190. Cambridge: Cambridge University Press, 2002.

55. Daft, R. L. and R. H. Lengel. Organizational information requirements, media richness and structural design. Management Science 32(5): 554-571, 1986.

56. Perrow, C. Organizational Analysis: A Sociological View. Monterey, CA: Wadsworth, 1970.

57. Bransford, J. D., A. L. Brown, and R. R. Cocking (Eds.). How People Learn: Brain, Mind, Experience, and School. National Academy Press: Washington, DC, 1999. Online: http://www.nap.edu/html/howpeople1/.

58. Haythornthwaite, C., K. J. Lunsford, G. C. Bowker, and B. Bruce. Challenges for research and practice in distributed, interdisciplinary, collaboration. To appear in C. Hine, (Ed.), New Infrastructures for Science Knowledge Production. Hershey, PA: Idea Group, forthcoming in February 2006.

59. Flowers, L. Talking across difference: Intercultural rhetoric and the search for situated knowledge. College Composition and Communication 55(1): 38-68, 2003.

60. Haythornthwaite, C., K. J. Lunsford, M. M. Kazmer, J. Robins, and M. Nazarova. The generative dance in pursuit of generative knowledge. Proceedings of the 36th Hawaii International Conference on System Sciences. Los Alamitos, CA: IEEE Computer Society, 2003.

61. Cummings, J. and S. Kiesler. KDI Initiative: Multidisciplinary Scientific Collaborations, 2004. Online: http://netvis.mit.edu/papers/NSF_KDI_report.pdf.

62. Haythornthwaite, C. Strong, weak and latent ties and the impact of new media. The Information Society 18(5): 385-401, 2002.

63. Granovetter, M. S. The strength of weak ties. American Journal of Sociology 78: 1360-1380, 1973. 
64. Swan, K., Shen, J. \& Hiltz, S. R. Assessment and collaboration in online learning. JALN 10(1): 2006.

65. Shen, J. Collaborative Examinations in Asynchronous Learning Networks: Field Experiments on Collaborative Learning through Online Assessments. Unpublished doctoral dissertation, Department of Information Systems, New Jersey Institute of Technology, 2005. Online: www.alnresearch.org.

66. Wu, D. and S. R. Hiltz. Predicting learning from asynchronous online discussions. Journal Asynchronous Learning Networks 8(2): 139-152, 2004.

67. Swan, K. Building learning communities in online courses: The importance of interaction. Education, Communication and Information 2(1): 23-49, 2002.

68. Saltz, J. S., S. R. Hiltz, M. Turoff, and K. Passerini. Measuring Student Participation in a WebBased Environment: A Framework for Developing New Tools. Proceedings of AMCIS, 2004.

69. Aviv, R., Z. Erlich, and G. Ravid. Reciprocity analysis of online learning networks. In J.C. Moore (Ed.), Elements of Quality Online Education: Engaging Communities, Wisdom from the Sloan Consortium, Vol. 2 in the Wisdom Series. Needham, MA: Sloan-C, 2005.

70. Haythornthwaite, C. Online personal networks: Size, composition and media use among distance learners. New Media and Society 2(2): 195-226, 2000.

71. Haythornthwaite, C. Exploring multiplexity: Social network structures in a computer-supported distance learning class. The Information Society 17(3): 211-226, 2001.

72. Haythornthwaite, C., B. Wellman, and L. Garton. Work and community via computer-mediated communication. In J. Gackenbach (Ed.) Psychology of the Internet, 199-226. San Diego, CA: Academic Press, 1998.

73. Herring, S. C. Computer-mediated communication on the Internet. Annual Review of Information Science and Technology 36: 109-168, 2002.

74. Smith, C. B., M. L. McLaughlin, K. K. Osborne. From terminal ineptitude to virtual sociopathy: Conduct control on Usenet. JCMC 2(4): 1996. Online: http:/www.ascusc.org/jcmc/vol2/issue4 /smith.html.

75. Spears, R., M. Lea, and T. Postmes. Social psychological theories of computer-mediated communication: Social pain or social gain? In W. P. Robinson and H. Giles (Eds.), New Handbook of Language and Social Psychology, 601-623. Chichester: Wiley, 2001.

76. Wellman, B., J. Salaff, D. Dimitrova, L. Garton, M. Gulia, and C. Haythornthwaite. Computer networks as social networks: Collaborative work, telework, and virtual community. Annual Review of Sociology 22: 213-238, 1996.

77. Haythornthwaite, C. and B. Wellman. Introduction: Internet in everyday life. The Internet in Everyday Life, 3-44. Oxford, UK: Blackwell, 2002.

78. Haythornthwaite, C. and A. Bregman. Affordances of persistent conversation: Promoting communities that work. In C. Haythornthwaite and M. M. Kazmer (Eds.), Learning, Culture and Community in Online Education: Research and Practice. NY: Peter Lang, 2004.

79. Erickson, T. Persistent conversation: An introduction. JCMC 4(4): 1999. Online: http://www.ascusC .org/jcmc/vol4/issue4/ericksonintro.html.

80. Rafaeli, S. and F. Sudweeks. Networked interactivity. Journal of Computer-Mediated Communication 2(4): 1997. Online: http://www.ascusc.org/jcmc/vol2/issue4/rafaeli.sudweeks.html.

81. DeSanctis, G. and M. S. Poole. Capturing the complexity in advanced technology use: Adaptive structuration theory. Organization Science 5(2): 121-47, 1994.

82. Haythornthwaite, C. Social networks and Internet connectivity effects. Information, Communication \& Society 8(2): 125-147, 2005.

83. Aviv, R., Z. Erlich, and G. Ravid. Mechanisms and architectures of online learning communities. In Kinshuk, L.C., E. Sutinen, D. Sampson, I. Aedo, L. Uden, and E. Kahekonen (Eds.), The 4th IEEE International Conference on Advanced Learning Technologies (ICALT), 400-404. Joensuu, Finland: IEEE, 2004. 
84. Lawton, P. and R. Montague. Teaching and Learning Online: LEEP's Tribal Gleanings. In C. Haythornthwaite and M. M. Kazmer (Eds.), Learning, Culture and Community in Online Education: Research and Practice, 197-213. NY: Peter Lang, 2004.

85. Hearne, B. G. and A. Nielsen. Catch a cyber by the tale: online orality and the lore of a distributed learning community. In C. Haythronthwaite and M. M. Kazmer (Eds.), Learning, Culture and Community in Online Education: Research and Practice, 59-87. NY: Peter Lang, 2004.

86. Ruhleder, K. Changing patterns of participation: Interactions in a synchronous audio+chat classroom. In C. Haythornthwaite and M. M. Kazmer (Eds.), Learning, Culture and Community in Online Education: Research and Practice, 163-176. NY: Peter Lang, 2004.

\section{ABOUT THE AUTHOR}

Caroline Haythornthwaite is Associate Professor at the Graduate School of Library and Information Science, University of Illinois at Urbana-Champaign. Her research interests center on what kinds of interactions support learning and work communities, and how computer media are used for such interaction. Studies examine: social networks and media use in co-located academic researchers, distance learners, and interdisciplinary research teams; online communication and community; and processes of collaboration, knowledge co-construction, and technology definition in research teams. Her work appears in the journals The Information Society, Journal of Computer-Mediated Communication, New Media \& Society, and Information, Communication and Society. She recently co-edited with Michelle M. Kazmer, Learning, Culture and Community in Online Education (2004, Peter Lang), and with Barry Wellman, The Internet in Everyday Life (2002, Blackwell). With Richard Andrews, she is currently co-editing the Handbook of Elearning Research (to be published in 2007, Sage). 